\title{
Oferta de serviços ecossistêmicos culturais na despoluição de rios urbanos em São Paulo
}

\author{
Adding cultural ecosystem services by urban river \\ depollution program in São Paulo city
}

Fábio Richard Flausino [a] [D, Amarilis Lucia Casteli Figueiredo Gallardo [a,b] [D]

[a] Universidade Nove de Julho (Uninove), São Paulo, SP, Brasil

[b] Universidade de São Paulo (USP), Escola Politécnica, São Paulo, SP, Brasil

Como citar: Flausino, F. R., \& Gallardo, A. L. C. F. (2021). Oferta de serviços ecossistêmicos culturais na despoluição de rios urbanos em São Paulo. urbe. Revista Brasileira de Gestão Urbana, v.13, e20200155.

https://doi.org/10.1590/2175-3369.013.e20200155

\section{Resumo}

A despoluição de rios representa uma iniciativa de requalificação do ambiente urbano. Córregos revitalizados abrangem ações de saneamento, mas ensejam expectativas de agregar valor à qualidade de vida. A gestão urbana tem o desafio de mensurar o bem-estar proporcionado por políticas públicas. Enquanto os serviços ecossistêmicos culturais representam os benefícios vivenciados no contato com ambientes naturais ou manejados, esse artigo objetiva analisar se esses serviços estão associados a benefícios não tangíveis percebidos pela população em um programa público de despoluição de rios em São Paulo. Os serviços culturais de interações pessoais, lazer, contemplação e espaço para manifestações são os mais percebidos frente àqueles que revelam influência para além do ambiente local e temporal como diversidade cultural e valores religiosos, espirituais e de educação. Recomenda-se que a avaliação de programas dessa natureza possa internalizar a perspectiva desses serviços ecossistêmicos como forma de fortalecer benefícios culturais à população nessa agenda de gestão urbana.

Palavras-chave: Serviços ecossistêmicos. Despoluição de rios e córregos urbanos. Serviços ecossistêmicos culturais. Programa Córrego Limpo. São Paulo.

\section{Abstract}

River depollution represents an initiative for requalifying urban environment. Revitalized streams encompass sanitation actions and also expectations of adding value to quality of life. Urban management has the challenge of measuring the well-being provided by public policies. While cultural ecosystem services represent the benefits from natural or managed environments, this paper aims at analyzing whether these services are linked with nontangible benefits perceived by population. With this purpose we selected a successful program in the São Paulo city. Cultural services related to personal interactions, leisure, contemplation and space for manifestations are

FRF é engenheiro ambiental, mestre em Gestão Ambiental e Sustentabilidade, e-mail: fabiorflausino@gmail.com ALCFG é professora universitária, Doutora em Engenharia, e-mail: amarilislcfgallardo@gmail.com 
the most perceived by local population. Whereas those services beyond the local and temporal environment as cultural diversity and religious, spiritual and educational values are the least perceived. We recommend that the evaluation of depollution programs can be based on cultural ecosystem approach as a way to strengthen cultural benefits for the population in this urban management agenda.

Keywords: Ecosystem services. depollution of urban rivers and streams. Cultural ecosystem services. Clean Stream Program. São Paulo city.

\section{Introdução}

Os rios correspondem a potenciais espaços nas cidades para vivenciar os benefícios do contato com a natureza, atendendo a necessidades materiais e espirituais da sociedade. 0 processo de urbanização, sobretudo nas grandes metrópoles, tem promovido a contínua degradação desses ecossistemas urbanos. Sob a perspectiva do paradigma atual das políticas de recuperação de rios urbanos, segundo Silva-Sánchez \& Jacobi (2012), esses ambientes ensejam oportunidades multifacetadas para a população urbana agregando objetivos para desenvolvimento econômico, proteção ambiental, promoção cultural e integração social.

Nesse contexto, os serviços ecossistêmicos representam uma gama variada de benefícios à sociedade, provenientes das funções que ecossistemas desempenham como regulação climática, controle de cheias, provisão de água, polinização e tratamento de resíduos, dentre outros (Costanza et al., 1997). Dentre esses serviços, são denominados serviços ecossistêmicos culturais (SEC) aqueles relacionados ao bem-estar obtido pelas pessoas em contato com a natureza, ou seja, representados por benefícios não-materiais como enriquecimento espiritual, desenvolvimento cognitivo, reflexão, recreação e experiências estéticas (MEA, 2005).

A abordagem dos serviços ecossistêmicos vem ganhando espaço no planejamento urbano e na agenda científica (Gómez-Baggethun \& Barton, 2013; Pulighe et al., 2016), mas, segundo Bullock et al. (2018), o mesmo não pode ser estendido para os SEC. A maioria dos estudos sobre qualidade de vida no ambiente urbano devota menor atenção aos benefícios não tangíveis da natureza (Hale et al., 2019). Porém, a importância substancial dos benefícios culturais para o bem-estar humano vem sendo reconhecida nas interações sociedade e ambiente (Bryce et al., 2016).

Os SEC, pela importância intrínseca para a população urbana (Xiao et al., 2017), podem, segundo Andersson et al. (2015), ser melhor apreciados nas cidades que os demais serviços ecossistêmicos, possibilitando aumentar a consciência da população sobre a manutenção dos ambientes urbanos recuperados e estimular as vivências humanas. Para Dou et al. (2019) a percepção dos SEC associados a rios e áreas verdes urbanas é fundamental para subsidiar projetos de revitalização urbana.

A despoluição de rios urbanos é um tema desafiador e atual, sobretudo na cidade de São Paulo com sua ampla rede de córregos deteriorados que drenam para os principais rios - Tietê e Pinheiros - poluídos que a atravessam (Jacobi et al., 2015). A preocupação para despoluir esses rios é antiga e recorrente na agenda do poder público. A pioneira campanha pela recuperação do rio Tietê, de 1992, apoiada por manifestações populares, permitiu a criação do Projeto Tietê, ainda vigente. Em 2019, o governo do estado de São Paulo anunciou investimentos financeiros destinados à despoluição do rio Pinheiros até 2022.

Sem dúvida uma das iniciativas públicas mais perenes no tema, refere-se ao Programa Córrego Limpo (PCL), parceria da Prefeitura Municipal de São Paulo (PMSP) e da Sabesp. Desde 2007, esse programa vem contribuindo para a despoluição de cursos de água urbanos por meio de uma série de ações estruturais e não-estruturais, com melhorias ao ecossistema urbano e benefícios tangíveis para a população paulistana (Souza et al., 2018a). A avaliação da eficácia do PCL é controversa, segundo Anelli (2015). Ramires Jr. et al. (2015) relatam resultados do PCL marcados por reincidência da poluição de alguns córregos e casos exitosos, principalmente, onde há efetiva governança colaborativa.

Nessa pesquisa explora-se como o processo de despoluição de córregos urbanos, no âmbito do PCL, e a consequente atração de frequentadores para paisagens revitalizadas, contribui com a promoção de SEC à 
sociedade. Estabelece-se como questão de pesquisa: Como um programa de despoluição de córregos urbanos oferece benefícios percebidos pela população que podem representar serviços ecossistêmicos culturais? 0 objetivo do artigo é analisar a oferta dos serviços ecossistêmicos culturais associados aos benefícios, percebidos pela população, no entorno de um córrego despoluído pelo Programa Córrego Limpo. Para tanto, selecionou-se como objeto de estudo o entorno, com áreas de lazer e espaços verdes, do córrego Charles de Gaulle, na zona oeste de São Paulo, considerado um dos casos de sucesso do PCL.

\section{Serviços ecossistêmicos culturais no planejamento urbano}

Os serviços ecossistêmicos representam os benefícios que as pessoas, direta ou indiretamente, usufruem das funções dos ecossistemas (Costanza et al., 1997). Esses serviços são classificados em quatro grandes categorias: provisão, regulação, de suporte e cultural (MEA, 2005).

Para Dickinson \& Hobbs (2017), os SEC representam os benefícios menos tangíveis obtidos dos ecossistemas. Vários trabalhos têm destacado que os SEC: despertam nas comunidades o valor da natureza como uma porta de entrada para o envolvimento público em questões ambientais (Daniel et al., 2012); permitem engajar as pessoas para aumentar a própria conscientização dos benefícios das demais categorias de serviços ecossistêmicos (com os quais os SEC possuem interdependência), principalmente no ambiente urbano (Jennings et al., 2016); não são distribuídos aleatoriamente pela paisagem, mas seguem padrões específicos em termos de intensidade, riqueza e diversidade (Plieninger et al., 2013).

Andersson et al. (2015) propõem que os SEC podem ser utilizados nos processos de planejamento urbano, ajudando a incorporar os serviços oferecidos por ecossistemas multifuncionais nas paisagens urbanas e nas mentes dos urbanistas e planejadores contribuindo para a promoção da sustentabilidade urbana. Para Cortinovis \& Geneletti (2018), sua inclusão é essencial para promover o desenvolvimento urbano sustentável, uma vez que as decisões sobre o uso do solo urbano vão condicionar a disponibilidade de oferta desses serviços fundamentais ao bem-estar da população. Considerar os benefícios de valores culturais associados aos ecossistemas é um diferencial para o gerenciamento dos recursos naturais em ambiente urbano (Fish et al., 2016).

Na perspectiva da gestão urbana, em consonância ao discutido por Andersson et al. (2015), Cortinovis \& Geneletti (2018) e Fish et al. (2016), os SEC podem ser utilizados como indicadores de avaliação de programas de despoluição de córregos para além dos indicadores de qualidade de água, beneficiando a população mutuamente em termos ambientais e culturais. Para a credibilidade desses projetos, deve-se considerar também a participação efetiva das partes interessadas, dando legitimidade à revitalização do ecossistema local, como destacado por Riechers et al. (2016).

\section{Avaliação de serviços ecossistêmicos culturais}

As dimensões dos SEC associam-se às características da região refletindo diretamente no bem-estar que provocam à população (Preston \& Raudsepp-Hearne, 2017). Há subjetividade no que tange ao contato direto com a natureza e ao bem-estar que esta interação confere ao indivíduo (Bryce et.al., 2016). Avaliar essa subjetividade tem sido um desafio para compreender a integração dos serviços ecossistêmicos aos benefícios sociais e, portanto, à oferta de SEC.

As principais categorias de SEC, e conceitos associados, segundo a classificação do MEA (2005), encontram-se na Tabela 1, bem como o número de citações sobre o tema em pesquisas bibliométricas realizadas por Cheng et al. (2019) e La Rosa et al. (2016). 
Tabela 1 - Descrição das categorias de serviços ecossistêmicos culturais e frequência observada na literatura.

\begin{tabular}{|c|c|c|c|}
\hline \multirow[t]{2}{*}{$\begin{array}{l}\text { Categoria de } \\
\text { SEC (MEA, 2005) }\end{array}$} & \multirow[t]{2}{*}{ Conceito } & \multicolumn{2}{|c|}{$\begin{array}{l}\text { Número de citações de SEC e } \\
\text { \% relativa de citações na } \\
\text { amostra da pesquisa }\end{array}$} \\
\hline & & $\begin{array}{l}\text { Cheng et al. } \\
(2019)\end{array}$ & $\begin{array}{l}\text { La Rosa et al. } \\
(2016)\end{array}$ \\
\hline $\begin{array}{l}\text { Diversidade } \\
\text { cultural }\end{array}$ & $\begin{array}{l}\text { A diversidade de ecossistemas é um dos fatores que } \\
\text { influencia a diversidade de culturas. }\end{array}$ & $18(6,1 \%)$ & $5(7,9 \%)$ \\
\hline $\begin{array}{l}\text { Valores } \\
\text { religiosos e } \\
\text { espirituais }\end{array}$ & $\begin{array}{l}\text { Muitas religiões atribuem valores espirituais e religiosos aos } \\
\text { ecossistemas ou seus componentes. }\end{array}$ & $60(20,5 \%)$ & $14(22,2 \%)$ \\
\hline $\begin{array}{l}\text { Sistemas de } \\
\text { conhecimento }\end{array}$ & $\begin{array}{l}\text { Os ecossistemas influenciam os tipos de sistemas de } \\
\text { conhecimento desenvolvidos por diferentes culturas. }\end{array}$ & $15(5,1 \%)$ & $4(6,3 \%)$ \\
\hline $\begin{array}{l}\text { Valores } \\
\text { educacionais }\end{array}$ & $\begin{array}{l}\text { Os ecossistemas e seus componentes e processos } \\
\text { fornecem a base para a educação formal e informal em } \\
\text { muitas sociedades. }\end{array}$ & $62(21,2 \%)$ & $9(14,3 \%)$ \\
\hline Inspiração & $\begin{array}{l}\text { Os ecossistemas fornecem uma rica fonte de inspiração } \\
\text { para arte, folclore, símbolos nacionais, arquitetura e } \\
\text { publicidade. }\end{array}$ & $22(7,5 \%)$ & $8(12,7 \%)$ \\
\hline $\begin{array}{l}\text { Valores } \\
\text { estéticos }\end{array}$ & $\begin{array}{l}\text { Muitas pessoas consideram beleza ou valor estético em } \\
\text { vários aspectos dos ecossistemas, como refletido no } \\
\text { suporte a parques, passeios panorâmicos e seleção de } \\
\text { locais de moradias. }\end{array}$ & $100(34,1 \%)$ & $22(34,9 \%)$ \\
\hline Relações sociais & $\begin{array}{l}\text { Os ecossistemas influenciam os tipos de relações sociais } \\
\text { que são estabelecidas em culturas particulares. }\end{array}$ & $20(6,8 \%)$ & $3(4,8 \%)$ \\
\hline Senso de lugar & $\begin{array}{l}\text { Muitas pessoas valorizam o senso do lugar associado a } \\
\text { características reconhecidas de seu ambiente, incluindo } \\
\text { aspectos do ecossistema. }\end{array}$ & $30(10,2 \%)$ & $6(9,5 \%)$ \\
\hline $\begin{array}{l}\text { Valores de } \\
\text { patrimônio } \\
\text { cultural }\end{array}$ & $\begin{array}{l}\text { Muitas sociedades valorizam muito a manutenção de } \\
\text { paisagens historicamente importantes (paisagens } \\
\text { culturais) ou de espécies culturalmente significativas. }\end{array}$ & $45(15,3 \%)$ & $12(19,0 \%)$ \\
\hline $\begin{array}{l}\text { Recreação e } \\
\text { ecoturismo }\end{array}$ & $\begin{array}{l}\text { As pessoas geralmente escolhem onde gastar seu tempo } \\
\text { com lazer baseado nas características das paisagens } \\
\text { naturais ou manejadas em uma área específica. }\end{array}$ & $180(61,4 \%)$ & $29(46,0 \%)$ \\
\hline
\end{tabular}

Nota: Cheng et al. (2019) realizaram uma pesquisa bibliométrica sobre métodos de avaliação de SEC no período de 2005 a 2017 , identificaram 20 métodos a partir de 293 artigos; La Rosa et al. (2016) realizaram uma pesquisa bibliométrica, até 2016, sobre indicadores para SEC e identificaram 63 artigos que abordam 37 indicadores de serviços ecossistêmicos em áreas urbanas. Fonte: preparada pelos autores.

Pela Tabela 1, observam-se os SEC em ambientes urbanos mais citados (La Rosa et al., 2016) e em ambientes diversos incluindo urbanos (Cheng et al., 2019). Em ambientes diversos há uma maior incidência de SEC de recreação e turismo, seguidos de valores estéticos. Os valores religiosos e espirituais, valores educacionais e de patrimônio cultural também estão entre as categorias de SEC que prevalecem no ambiente urbano. Bertran \& Rehdanz (2015), ao avaliarem a percepção de usuários de quatro parques urbanos de cidades europeias, destacam turismo e apreciação aestética como relevantes SEC denotando a importância das oportunidades de recreação para o bem-estar humano. Plieninger et al. (2013) também reforçam que, em nível de comunidade, são considerados os SEC mais importantes aqueles relacionados a valores aestéticos, relações sociais e valores educacionais.

Hale et al. (2019) ao analisarem os SEC providos por rios em diversas paisagens socioecológicas perceberam que se associam mais às características das paisagens do que propriamente às categorias gerais de SEC, como as descritas pelo MEA (2005). Ainda para esses autores não apenas a diversidade como as pessoas interagem com as paisagens, mas também quais recursos das paisagens suportam seus usos, condicionam essa variedade de SEC.

Os SEC têm sido avaliados com uso de técnicas de geoprocessamento (Plieninger et al., 2013), ferramentas como Lidar (Light detection and ranging - sistema a laser terrestre para obtenção de dados espaciais) (Berkel et al., 2018), mídia social (Hale et al., 2019) mas, principalmente, por métodos 
interpretativos para compreensão da atitude do indivíduo em relação ao meio ambiente (Stålhammar \& Pedersen, 2017; La Rosa et al., 2016).

A relação dos indivíduos com o ambiente revela o significado da avaliação dos SEC em um contexto social (Fish et. al., 2016). Avaliar a oferta de SEC está diretamente relacionada à mensuração dos benefícios obtidos pela sociedade em processos de recuperação de ambientes degradados (Hegetschweiler et. al., 2017), como a revitalização de drenagens urbanas por ações de despoluição.

\section{Método}

Essa pesquisa qualitativa, de objetivo exploratório, foi desenvolvida com vistas a fomentar a ampliação da discussão do tema no país. A busca pelo termo SEC em consulta à Biblioteca Digital Brasileira de Teses e Dissertações (BDTD), em agosto de 2020, revelou apenas cinco dissertações defendidas entre 2017 e 2020. Na mesma data, a consulta na base eletrônica Web of Science Core Collection (WoS), a partir do mesmo termo, permitiu identificar 755 artigos, e quando agregada a palavra-chave "Brazil" foram encontrados 22 artigos, no período de 2014 a 2020. A essa amostra de 22 artigos foram aplicados dois novos filtros 'urbano' e 'cidades' que revelaram, respectivamente, nenhum e quatro artigos, denotando esse ser um tema de fronteira do conhecimento no país.

Assim, selecionou-se um estudo de caso, considerando dados de: a) pesquisa bibliográfica que fornece a base teórica para a compreensão do tema; b) análise documental sobre o PCL; c) levantamento primário de dados por meio de entrevistas, que segundo a literatura (Cheng et al., 2019) é a técnica mais empregada para avaliar SEC. A construção da amostra sobre quem e quantos entrevistar fundamentou-se na técnica bola de neve (Vinuto, 2014; Ribeiro et al., 2018). A análise dos dados foi realizada por meio de software para tratamento de informações de análise de conteúdo de dados textuais (Souza et al., 2018b; Avelar et al., 2019).

\section{Breve caracterização da área de estudo: entorno do córrego Charles de Gaulle}

O escopo do programa de recuperação ambiental de cursos d'água e fundos de vale ou, simplesmente, Programa Córrego Limpo (PCL), envolve a urbanização de favelas, remoção de comunidades das margens dos rios, limpeza do leito e das galerias (responsabilidade da PMSP), ampliação e modernização da coleta e tratamento de efluentes e resíduos pela instalação, operação e disponibilização de redes coletoras de esgotos para afastamento, assim como o diagnóstico de lançamentos de efluentes clandestinamente nos rios (responsabilidade Sabesp) (Sabesp, 2013). Essas ações são tomadas de modo integrado, buscando atingir a despoluição dos córregos do município de São Paulo (Anelli, 2015).

A primeira fase do PCL visou atender áreas de parques urbanos com córregos, buscando a melhoria das suas águas e margens, atendendo a uma demanda da população por áreas verdes limpas para lazer (Sabesp, 2013), o que se coaduna aos preceitos dos SEC.

0 córrego Charles de Gaulle (Figura 1), insere-se em uma bacia com área de 0,75 km² com uma população aproximada de 8.500 habitantes, localizado no bairro de Pirituba, a aproximadamente $18 \mathrm{~km}$ do centro de São Paulo. 


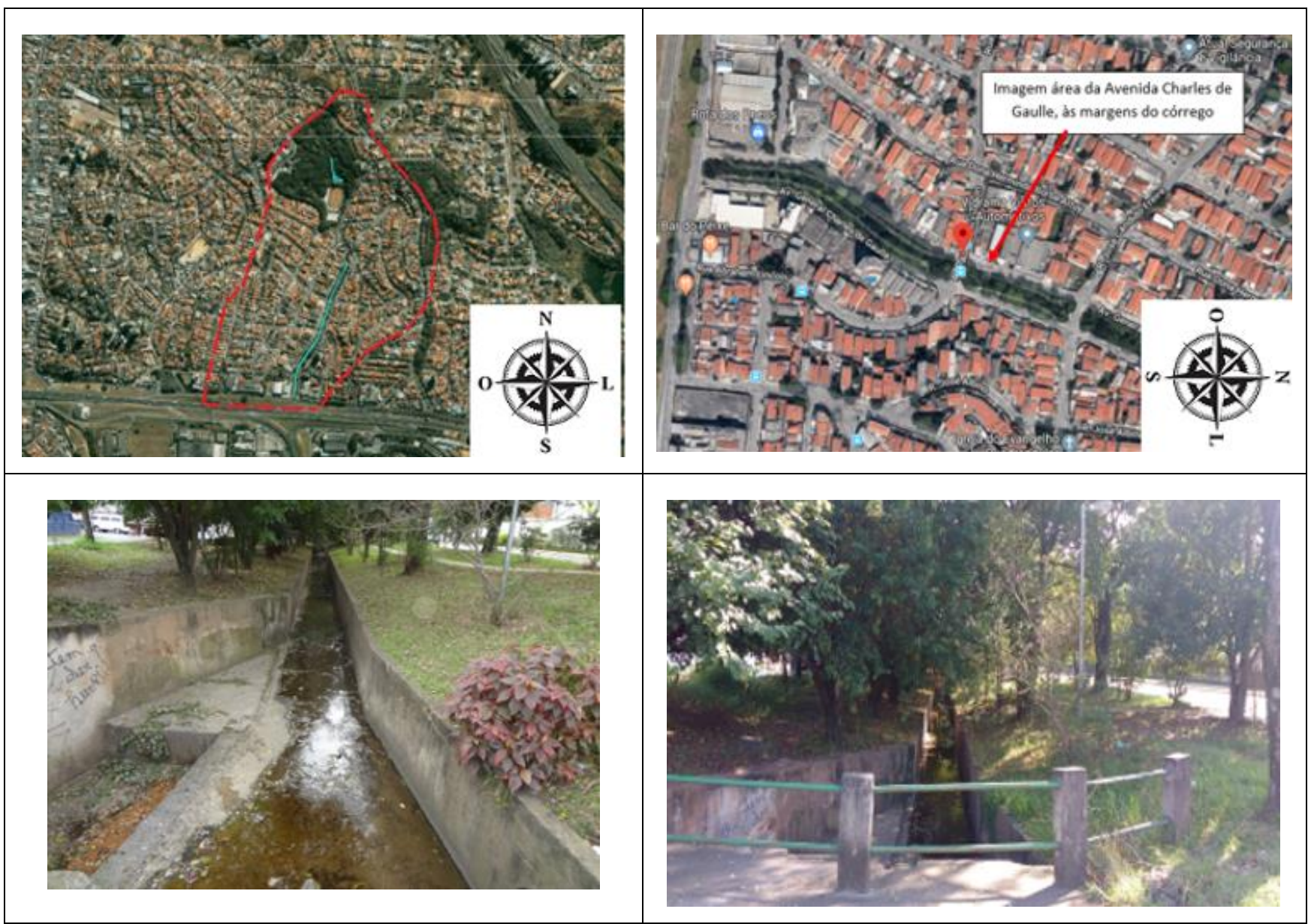

Figura 1 - Localização e detalhes do córrego Charles de Gaulle. Nota: A imagem acima à esquerda apresenta a bacia do córrego Charles de Gaulle delimitada pela linha tracejada em vermelho em que a linha contínua azul representa a extensão do córrego (Fonte: Signos - Sistema de Informações Geográficas no Saneamento - da Sabesp). A imagem acima à direita apresenta uma vista aérea do entorno do córrego (Signos - Sabesp). As duas imagens inferiores apresentam detalhes do córrego despoluído e da vegetação do entorno. Fonte: os autores.

0 processo de acompanhamento da qualidade da água do córrego Charles de Gaulle iniciou-se, em março de 2007, com valor do parâmetro de qualidade de água - Demanda Bioquímica de Oxigênio (DBO) de $84 \mathrm{mg} / \mathrm{L}$. De acordo com a Resolução Conama 357/2005, o valor de DBO deve estar inferior a $30 \mathrm{mg} / \mathrm{L}$ para que o córrego seja considerado despoluído. Desde 2008, o córrego vem se mantendo despoluído com valores máximos de DBO de $25 \mathrm{mg} / \mathrm{L}$.

O planejamento para despoluição do córrego compreende as seguintes etapas: diagnóstico para identificação de lançamentos clandestinos em galerias de águas pluviais; manutenção das redes coletoras de esgotos através de desobstruções e reparos de vazamentos; execução de ligações domiciliares e industriais de esgotos, obras de remanejamento, interligações e prolongamento de redes coletoras de esgotos; palestras e reuniões com a comunidade local para disseminação dos conceitos de governança colaborativa para fomentar a auto-gestão com vistas à manutenção do córrego na condição de despoluído; construção de calçamentos e projeto paisagístico nas margens do curso de água canalizado (Sabesp, 2013).

O direcionamento dos esgotos para as redes coletoras e a limpeza do leito do córrego, alterou as características visuais da área, possibilitando a criação de um novo ambiente de interação social para a região. A avenida Charles de Gaulle está às margens do trecho aberto do córrego, onde o processo de revitalização criou uma faixa para a população desenvolver atividades físicas e sociais (Figura 1). 


\section{Coleta de dados: entrevistas semiestruturadas}

Dois trabalhos recentes de revisão de literatura, um sobre avaliação de SEC (Cheng et al., 2019) e outro sobre sua identificação em áreas verdes urbanas (Hegetschweiler et al., 2017), destacam as entrevistas e/ou questionários como os métodos mais empregados para explorar o tema. De acordo com Cheng et al. (2019), dos 262 artigos analisados, a maioria (65) utilizou entrevistas como procedimento para aquisição de dados primários sobre SEC. As entrevistas para levantamento da percepção da população sobre SEC em áreas urbanas foram empregadas por Ko \& Son (2018), em uma cidade na Coreia, por Riechers et al. (2016), em Berlim, e por Dou et al. (2019), em Beijing. Para Bennett (2016), a percepção dos indivíduos colabora para políticas de conservação. Bertram \& Rehdanz (2015) utilizaram protocolos de avaliação da percepção e da atitude no uso de áreas verdes urbanas para a identificação e qualificação dos SEC no planejamento urbano.

Para essa pesquisa elaborou-se um roteiro para as entrevistas semiestruturadas, compilado a partir do referencial da literatura sobre percepção e atitude, a partir dos trabalhos de atitude e de afetividade de Cohen \& Andrade (2004), de afetividade de Shimpi \& Stuart (2004), de atitude e diversão de Nysveen et al. (2005) e de identificação social de Laverie et al. (2002), complementados por trabalhos que discutem SEC em áreas urbanas, como apresentado na Tabela 2.

Tabela 2 - Roteiro para entrevistas semiestruturadas

\begin{tabular}{|c|c|}
\hline Perguntas aos frequentadores do entorno do córrego Charles de Gaulle & referencial \\
\hline 1. Como se sente ao observar o processo de revitalização do córrego? & $1 ; 2$ \\
\hline 2. Como se sente em relação do córrego antes da intervenção? & $1 ; 2$ \\
\hline 3. Como definiria do córrego em poucas palavras? E em uma palavra? & 1 \\
\hline 4. Você recomendaria este bairro para outra pessoa morar? Por quê? & 1 \\
\hline 5. Qual o significado e quais os sentimentos que esse córrego representa e despertam? & $2 ; 3$ \\
\hline 6. Após a despoluição do córrego houve episódios de enchentes na região? & 4 \\
\hline $\begin{array}{l}\text { 7. Quais benefícios da despolvição do córrego podem ser considerados mais e menos } \\
\text { importantes? }\end{array}$ & $2,3,4$ \\
\hline 8. É possível melhorar a despolvição do córrego agregando outros benefícios? & 3 \\
\hline 9. Houve aumento ou diminuição de insetos e/ou roedores após a despolvição do córrego? & 4 \\
\hline $\begin{array}{l}\text { 10. Pense na sua relação com a revitalização do córrego e avalie a afirmação: "Esse córrego } \\
\text { revitalizado me faz sentir mais próximo à natureza, tenho sentimento de identidade e } \\
\text { pertencimento a esse lugar". Explique. }\end{array}$ & 2,4 \\
\hline $\begin{array}{l}\text { 11. Pense na sua relação com a revitalização do córrego e avalie a afirmação: "Esse córrego } \\
\text { revitalizado me faz considerar que aqui podemos desenvolver atividades culturais, artísticas } \\
\text { e/ou outras de recreação e interação". Explique. }\end{array}$ & $1,2,3,4$ \\
\hline $\begin{array}{l}\text { 12. Pense na sua relação com a revitalização do córrego e avalie a afirmação: "Quando } \\
\text { observo esse córrego revitalizado eu tenho uma sensação de conforto e bem-estar ao } \\
\text { observar esta paisagem". Explique }\end{array}$ & 2,4 \\
\hline $\begin{array}{l}\text { 13. Pense na sua relação com a revitalização do córrego e avalie a afirmação: "Eu considero } \\
\text { que muitas pessoas vêm passear aqui pois apreciam a beleza desse córrego revitalizado". } \\
\text { Explique. }\end{array}$ & $2,3,4$ \\
\hline $\begin{array}{l}\text { 14. Pense na sua relação com a revitalização do córrego e avalie a afirmação: "Eu escolho } \\
\text { passar meu tempo livre nesse córrego revitalizado pois esse córrego me dá oportunidade de } \\
\text { contato com a natureza". Explique. }\end{array}$ & $1,2,4$ \\
\hline $\begin{array}{l}\text { 15. Como avalia o aproveitamento das áreas de lazer criadas no projeto de revitalização do } \\
\text { córrego (ciclo faixa, áreas com vegetação)? }\end{array}$ & 2,3 \\
\hline
\end{tabular}

Nota: Referencial teórico sobre percepção e atitude que fundamentaram a formulação das questões: ${ }^{1}$ atitude e de afetividade (Cohen \& Andrade, 2004), ${ }^{2}$ afetividade de Shimpi \& Stuart (2004), ${ }^{3}$ atitude e diversão (Nysveen et al., 2005), 4 identificação social (Laverie et al., 2002). Fonte: os autores.

A definição do número de entrevistados fundamentou-se na técnica de bola de neve. Essa técnica determina que os critérios sejam definidos pela busca da participação de pessoas inseridas no contexto da pesquisa para representar o conjunto das condições observadas (Vinuto, 2014). De acordo com Ribeiro et al. (2018), o ponto de saturação caracteriza-se no momento em que aspectos relevantes do estudo sejam satisfeitos em conformidade aos conceitos teóricos estabelecidos como premissas da pesquisa. Assim, a técnica bola de neve permitiu construir a amostra da pesquisa com relação a: a) quem entrevistar: o 
entrevistado indica novos informantes que atendam o critério de ser frequentador do entorno do córrego; b) quantos entrevistar: foi utilizada a saturação qualitativa permitindo ao pesquisador reconhecer quando não era mais necessário agregar informantes para a pesquisa. Desse modo, foram realizadas 26 entrevistas com frequentadores do entorno do córrego Charles de Gaulle (Figura 1), entre janeiro e julho de 2018.

\section{Análise de dados}

Utilizou-se a análise textual que, segundo Nascimento \& Menandro (2006), refere-se a uma análise do material verbal transcrito para quantificar informação qualitativa, por meio do uso do software Iramuteq (Interface de R pourlês Analyses Multidimensionnelles de Textes et de Questionnaires). 0 Iramuteq permite uma análise estatística de textos para agrupar e organizar a frequência das palavras mencionadas nas entrevistas e, assim, favorecer a análise de conteúdo (Camargo \& Justo, 2013).

Foram realizada duas análises pelo Iramuteq: a nuvem de palavras que é uma análise lexical simples para identificação das palavras-chave; e a classificação hierárquica descendente (CHD), análise multivariada que permite analisar mais de uma variável ao mesmo tempo, ou seja, visa definir classes de palavras em um mesmo contexto, diferenciando-as do contexto de outras mencionadas, por meio de um dendograma (Camargo \& Justo, 2013).

O software permitiu, após a transcrição das entrevistas, a análise lexicográfica que gerou a CHD. De acordo com Oltramari \& Camargo (2010), a organização e a classificação dos textos podem evidenciar potenciais representações sociais. Segundo Souza et al. (2018b) são três as etapas envolvidas para gerar a CHD: preparação e codificação do texto coletado, o processamento dos dados que geram a CHD e a posterior interpretação das classes. As classes do dendograma são fornecidas pelo software, mas sua análise é realizada pela interpretação do pesquisador com o suporte do referencial metodológico (Avelar et al., 2019). Após a análise da codificação preparada pelo software Iramuteq, foi realizada uma nova leitura das entrevistas à luz da literatura para, então, interpretar e denominar as classes que representam a análise qualitativa dos dados. As palavras destacadas no dendograma e sua respectiva inserção nos textos das entrevistas permitiu estabelecer, como discutido por Souza et al. (2018b), a associação entre a percepção da população local e os SEC, indicando potenciais representações sociais. A configuração das classes está diretamente relacionada à análise léxica das palavras mais citadas, permitindo a verificação do contexto em que foram empregadas para identificar seu significado enquanto SEC.

A nuvem de palavras foi explorada como uma ferramenta complementar de análise textual permitida por outra análise mais sofisticada (Heimerl et al., 2014), no caso, a CHD. A frequência das principais palavras-chave, organizadas pelo software, foi analisada, revisitando o conteúdo das respostas dos entrevistados, de modo a refletir a percepção geral da população acerca do projeto em termos de qualificação positiva e negativa no contexto das entrevistas realizadas.

Os resultados dessas análises estatísticas foram, então, interpretados para evidenciar os benefícios percebidos pela população e sua associação às categorias de SEC identificadas em literatura (Tabela 1).

\section{Percepção da população sobre a oferta de serviços ecossistêmicos culturais na despolvição do córrego Charles de Gaulle}

A Figura 2 representa a análise da percepção da população acerca da despoluição do córrego Charles de Gaulle. 


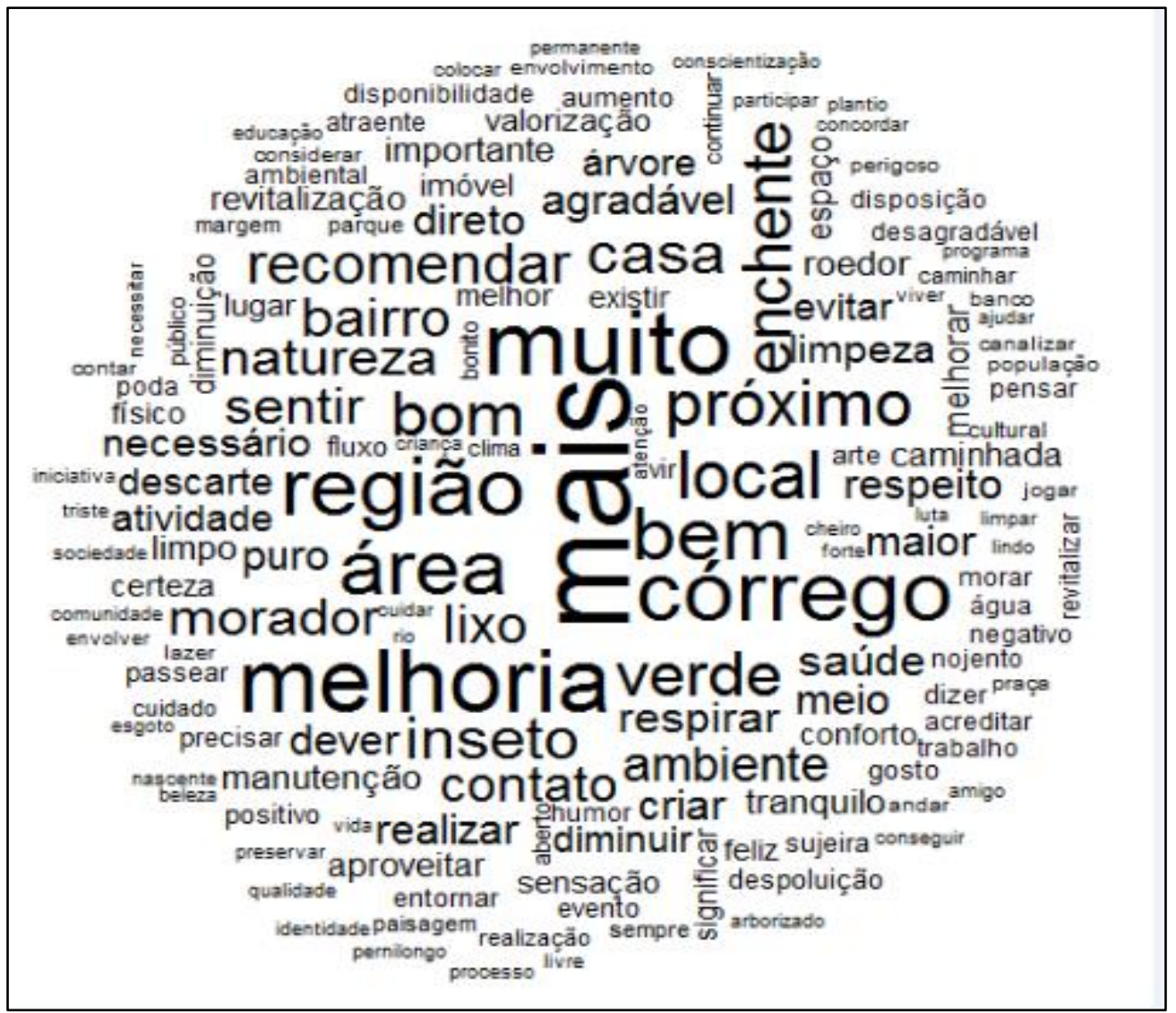

Figura 2 - Nuvem de palavras da análise das entrevistas com a população acerca da despolvição do córrego Charles de Gaulle. Fonte: os autores.

As palavras-chave mais frequentes da Figura 2 foram analisadas quanto ao contexto das entrevistas como apresentado na Tabela 3.

Tabela 3 - Análise do contexto das palavras-chave mais citadas na nuvem de palavras

\begin{tabular}{|c|c|c|c|c|c|}
\hline \multirow[b]{2}{*}{$\begin{array}{l}\text { Palavra- } \\
\text { chave }\end{array}$} & \multicolumn{5}{|c|}{ Contexto de inserção da palavra-chave durante a entrevista } \\
\hline & Positivo & & Negativo & & $\begin{array}{l}\text { Neutro ou } \\
\text { indiferente }\end{array}$ \\
\hline mais & 24 & $\begin{array}{l}\text { Qualidade ambiente e } \\
\text { do bairro }\end{array}$ & 14 & $\begin{array}{l}\text { Falta de cuidados, de } \\
\text { melhorias, de } \\
\text { engajamento da } \\
\text { população, de lazer e } \\
\text { fiscalização }\end{array}$ & 10 \\
\hline muito & 21 & $\begin{array}{l}\text { Melhoria do local, da } \\
\text { paisagem, do verde e } \\
\text { do bairro }\end{array}$ & 8 & $\begin{array}{l}\text { Aumento de insetos, } \\
\text { presença de lixo, falta de } \\
\text { espaço e a melhorar no } \\
\text { projeto }\end{array}$ & 9 \\
\hline melhoria & 15 & $\begin{array}{l}\text { Melhoria da saúde e da } \\
\text { arborização }\end{array}$ & 20 & $\begin{array}{l}\text { Necessidade de melhorias } \\
\text { no projeto }\end{array}$ & 2 \\
\hline região & 33 & $\begin{array}{l}\text { Valorização da região } \\
\text { para atrair pessoas, } \\
\text { eventos, com redução } \\
\text { de vetores de doença }\end{array}$ & 0 & & 1 \\
\hline área & 22 & $\begin{array}{l}\text { Áreas verdes valorizam o } \\
\text { espaço do córrego } \\
\text { revitalizado }\end{array}$ & 8 & $\begin{array}{l}\text { Falta de manutenção das } \\
\text { áreas verdes }\end{array}$ & 2 \\
\hline córrego & 8 & $\begin{array}{l}\text { O córrego é visto como } \\
\text { um elemento que foi } \\
\text { melhorado e atrai } \\
\text { pessoas e atividades }\end{array}$ & 15 & $\begin{array}{l}\text { Córrego é visto ainda } \\
\text { como fonte de problemas } \\
\text { relacionados a odor e } \\
\text { vetor de contaminação }\end{array}$ & 8 \\
\hline
\end{tabular}

(Continua) 


\begin{tabular}{|c|c|c|c|c|c|}
\hline bom & 11 & $\begin{array}{l}\text { O córrego e o bairro são } \\
\text { descritos como bons }\end{array}$ & & & 4 \\
\hline bem & 17 & $\begin{array}{l}\text { O córrego revitalizado } \\
\text { provoca sensação de } \\
\text { bem-estar e são } \\
\text { associadas } \\
\text { características positivas } \\
\text { ao córrego }\end{array}$ & & & 4 \\
\hline local & 22 & $\begin{array}{l}\text { Respeito ao ambiente } \\
\text { local }\end{array}$ & 1 & $\begin{array}{l}\text { Local precisa de } \\
\text { melhorias }\end{array}$ & 2 \\
\hline próximo & 21 & $\begin{array}{l}\text { Proximidade do parque } \\
\text { e do contato com a } \\
\text { natureza }\end{array}$ & & & \\
\hline enchente & 6 & $\begin{array}{l}\text { Não há mais problemas } \\
\text { com enchentes }\end{array}$ & & & \\
\hline casa & 22 & $\begin{array}{l}\text { Aspectos positivos de ter } \\
\text { um parque perto de } \\
\text { casa }\end{array}$ & & & 1 \\
\hline verde & 19 & $\begin{array}{l}\text { Aspectos positivos de ter } \\
\text { o verde próximo à casa }\end{array}$ & 5 & $\begin{array}{l}\text { Falta de manutenção nas } \\
\text { áreas verdes }\end{array}$ & \\
\hline
\end{tabular}

Fonte: os autores.

Pela análise da Tabela 3 e da Figura 2 observa-se que os entrevistados possuem, em sua maioria, uma percepção positiva do projeto, destacando melhorias em termos de valorização local e qualidade ambiental que vem permitindo um uso mais intenso da área para atividades diversas. Entretanto, também são revelados aspectos negativos, principalmente, referentes a problemas de manutenção da área, limitação de áreas de lazer e da visão do córrego como fonte de problemas; dois entrevistados mencionam que seria melhor ter o córrego canalizado e tamponado. Essa análise é corroborada pelas respostas fornecidas às perguntas (vide Tabela 2): 1) em que 15 entrevistados demonstram sentimentos positivos contra 11 com negativos frente ao processo de revitalização; 4) a grande maioria - 23 frequentadores - recomenda o bairro, enquanto apenas dois não recomendariam e um optou por não responder; e 5) os sentimentos despertados são positivos para a grande maioria (20) e de indiferença para seis entrevistados.

A Figura 3 ilustra o dendograma da CHD com as seis classes de palavras geradas pelo software e interpretadas à luz das entrevistas. 


\section{Percepção da população sobre a oferta de serviços ecossistêmicos culturais na despoluição do córrego Charles de Gaulle}

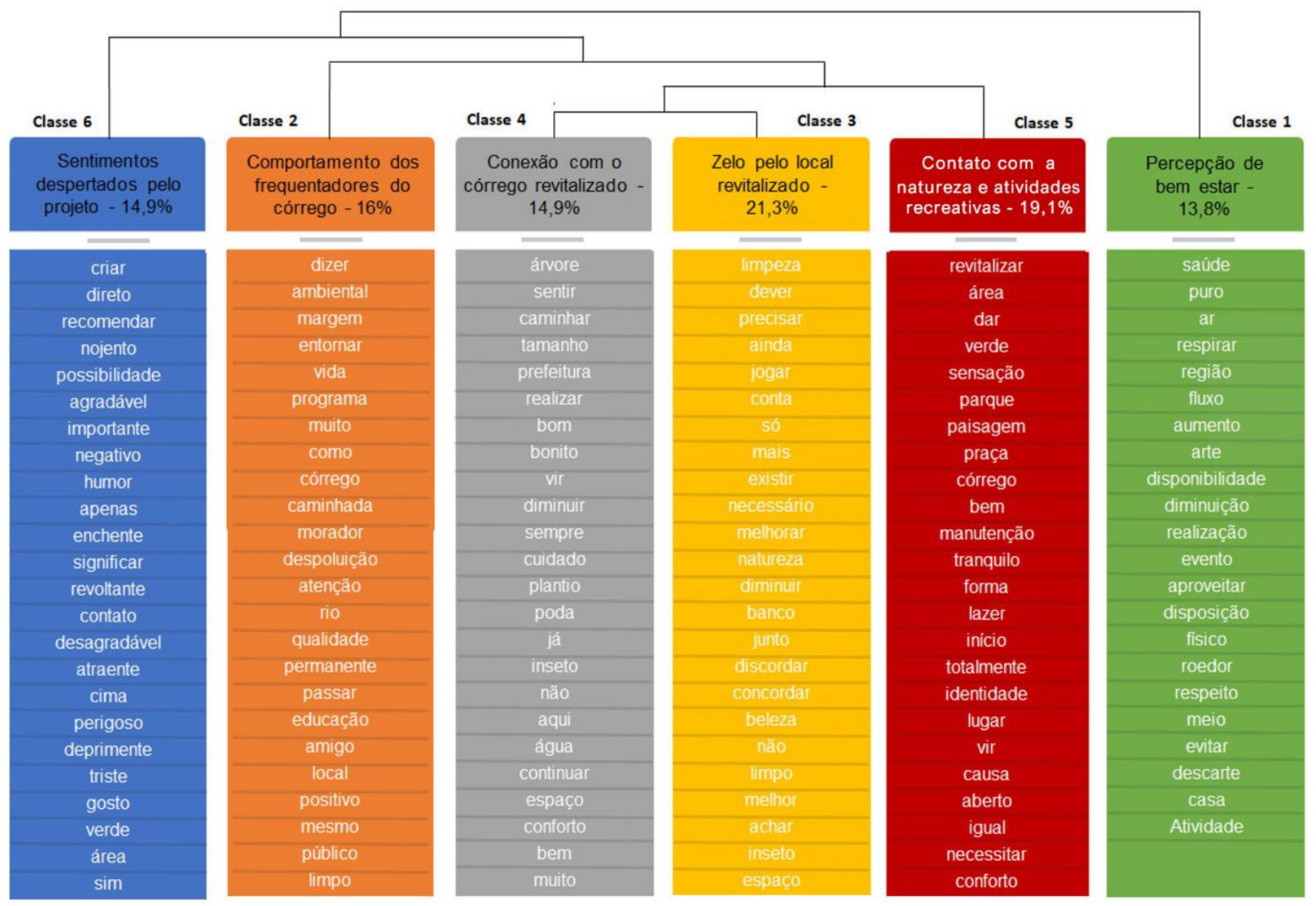

Figura 3 - Dendograma do conteúdo das entrevistas com a população acerca da despolvição do córrego Charles de Gaulle.

Fonte: os autores.

Conforme a Figura 3, há uma associação direta entre as classes 3 e 4 demonstrando a relação entre a necessidade do zelo para a manutenção do projeto de revitalização do córrego e a conexão estabelecida pelas sensações, muitas de bem-estar, que remetem ao córrego revitalizado, respectivamente. Essas duas classes agrupadas relacionam-se à classe 5 , que reforça a possibilidade do contato com a natureza e de desenvolver atividades recreativas. Essas três classes relacionam-se à classe 2, que abrange o comportamento dos frequentadores do córrego e a sua representatividade para a região. Essas classes agrupadas relacionam-se à classe 6 que denota os sentimentos dos frequentadores sobre os resultados do processo de despoluição. A classe 6 representa sentimentos ambíguos - para alguns de melhoria de qualidade de vida e avanço quanto à situação pretérita à intervenção, mas para outros denotando que o projeto não foi satisfatório. Por fim, a classe 1 abrange todas as demais classes consolidando um significado de bem-estar a esse processo de despoluição do córrego; isso é corroborado pelo fato dessa classe ser a mais distante com relação à classe 6, que representa os sentimentos mais ambíguos quanto ao projeto.

A Tabela 4 complementa a análise feita a partir do dendograma considerando-se as respostas às perguntas 10 a 15 (Tabela 2). 
Tabela 4 - Análise das perguntas referentes aos SEC

\begin{tabular}{|c|c|c|c|c|c|}
\hline \multirow[t]{2}{*}{ Perguntas } & \multicolumn{4}{|c|}{ Percepção dos frequentadores } & \multirow{2}{*}{$\begin{array}{l}\text { Principais trechos das respostas dos } \\
\text { frequentadores }\end{array}$} \\
\hline & positiva & negativa & indiferente & $\begin{array}{l}\text { sem } \\
\text { resposta }\end{array}$ & \\
\hline $\begin{array}{l}10 \text { - "sentimento } \\
\text { de identidade e } \\
\text { pertencimento }\end{array}$ & 20 & 1 & 4 & 1 & $\begin{array}{l}\text { "proximidade com a natureza"; "luta dos } \\
\text { moradores permitiu a despoluição do córrego"; } \\
\text { "qualidade de vida"; "melhora do ar"; "vista } \\
\text { maravilhosa"; "me sinto bem"; "parcialmente, } \\
\text { precisa de melhorias"; }\end{array}$ \\
\hline $\begin{array}{l}11 \text { - "atividades } \\
\text { culturais... de } \\
\text { recreação e } \\
\text { interação" }\end{array}$ & 11 & 7 & 6 & 2 & $\begin{array}{l}\text { "foram realizadas várias atividades"; "feira de } \\
\text { atividades de Pirituba"; "não existe espaço } \\
\text { suficiente"; "precisar melhorar calçada e poda"; } \\
\text { "espaço ideal"; "falta espaço para hortas e } \\
\text { pomares"; "ambiente une pessoas à natureza"; }\end{array}$ \\
\hline $\begin{array}{l}12 \text { - sensação } \\
\text { de conforto e } \\
\text { bem-estar" }\end{array}$ & 14 & 7 & 3 & 2 & $\begin{array}{l}\text { "natureza conservada nos traz bem-estar"; } \\
\text { "nada é só propaganda"; "saúde do corpo e } \\
\text { espírito"; "pássaros, árvores floridas e amigos"; } \\
\text { "andar e passear"; "excesso de sujeira"; } \\
\text { "quando está limpo é melhor que antes"; "o } \\
\text { córrego não propicia conforto"; "tem que fazer } \\
\text { melhorias"; }\end{array}$ \\
\hline $\begin{array}{l}13 \text { - "muitas } \\
\text { pessoas } \\
\text { apreciam a } \\
\text { beleza..." }\end{array}$ & 12 & 7 & 2 & 5 & $\begin{array}{l}\text { "áreas verdes estão sendo invadidas"; "pessoas } \\
\text { ficam deslumbradas com verde e calma do } \\
\text { lugar"; "quando não está limpo, chamamos a } \\
\text { prefeitura"; "não existe atrativos para visitantes"; } \\
\text { "a área é plana"; "vem gente de longe por } \\
\text { causa da área verde"; "paisagem linda"; }\end{array}$ \\
\hline $\begin{array}{l}14 \text { - "eu escolho } \\
\text { passar tempo } \\
\text { livre pelo } \\
\text { contato com a } \\
\text { natureza" }\end{array}$ & 12 & 2 & 5 & 6 & $\begin{array}{l}\text { "espaço para caminhada, leitura, exercícios } \\
\text { físicos, passear crianças e animais"; } \\
\text { "caminhada"; "sem dúvida"; "sujeira e grama } \\
\text { alta"; "área plana"; "faz bem ao espírito"; "não } \\
\text { existe beleza"; "contato com a natureza"; "bom } \\
\text { para andar, não para olhar"; "sinto felicidade"; }\end{array}$ \\
\hline $\begin{array}{l}15 \text { - "áreas de } \\
\text { lazer" }\end{array}$ & 11 & 8 & 6 & 1 & $\begin{array}{l}\text { "nomear padrinhos para cuidar do local"; "falta } \\
\text { aparelhos de ginástica e bancos"; "boa } \\
\text { iniciativa da faixa de caminhada"; "iniciativa } \\
\text { ainda muito tímida na região, mas } \\
\text { recompensadora e necessária"; "seria mais } \\
\text { utilizado se tivesse mais opções de lazer"; "falta } \\
\text { segurança"; "muitos idosos frequentam"; "falta } \\
\text { integração entre áreas verdes do bairro"; } \\
\text { "deveria melhorar"; "precisa de manutenção"; } \\
\text { "linda a faixa para andar". "árvores } \\
\text { maravilhosas"; "poderia melhorar". }\end{array}$ \\
\hline
\end{tabular}

Fonte: os autores.

A análise da Figura 3 e da Tabela 4 permite identificar características de senso de pertencimento, de identidade, de uso para lazer, de espaço para cultura, de orgulho, de patrimônio a partir da percepção dos frequentadores sobre os benefícios advindos das melhorias promovidas pela despoluição do córrego.

\section{Perspectiva para a manutenção e ampliação da oferta de serviços ecossistêmicos culturais na despoluição de córregos urbanos}

A despoluição do córrego Charles de Gaulle mostrou-se um caso de sucesso do PCL para além das melhorias quanto à qualidade de água em corpos hídricos urbanos, agregando a oferta de SEC para a sociedade, como esperado em políticas de planejamento urbano, conforme destacado por GómezBaggethun \& Barton (2013) e La Rosa et al. (2016).

A Tabela 5 apresenta a associação entre as categorias de SEC (MEA, 2005), os benefícios destacados pelos frequentadores do córrego Charles de Gaulle e as potenciais representações sociais associadas à percepção ambiental desses entrevistados, como discutido por Macedo-Silva et al. (2016). A teoria das 
representações sociais vem sendo empregada para analisar a percepção ambiental da relação entre os indivíduos e o ambiente (Dictoro et al., 2016).

Tabela 5 - Associação entre as categorias de SEC (MEA, 2005) e os benefícios percebidos pela população do entorno do córrego Charles de Gaulle

\begin{tabular}{|c|c|c|c|}
\hline \multirow{2}{*}{$\begin{array}{l}\text { Categoria de SEC } \\
\text { (MEA, 2005) }\end{array}$} & \multicolumn{3}{|c|}{ Córrego Charles de Gaulle } \\
\hline & Observado & $\begin{array}{l}\text { Benefícios percebidos pela } \\
\text { população }\end{array}$ & Potenciais representações sociais \\
\hline Diversidade cultural & Não & & \\
\hline $\begin{array}{l}\text { Valores religiosos e } \\
\text { espirituais }\end{array}$ & Não & $\begin{array}{l}\text { A única menção à religião é } \\
\text { colocada de modo negativo } \\
\text { como atraindo roedores e insetos }\end{array}$ & \\
\hline $\begin{array}{l}\text { Sistemas de } \\
\text { conhecimento }\end{array}$ & Não & & \\
\hline Valores educacionais & Não & & \\
\hline Inspiração & Sim & $\begin{array}{l}\text { Há menções sobre eventos locais } \\
\text { na área }\end{array}$ & $\begin{array}{l}\text { "embora eventos tenham sido } \\
\text { realizados, é preciso melhorias para } \\
\text { ampliar a inspiração por arte e } \\
\text { cultura na área" }\end{array}$ \\
\hline Valores estéticos & Sim & $\begin{array}{l}\text { O uso do local para passeios e } \\
\text { caminhadas }\end{array}$ & $\begin{array}{l}\text { "a área inspira caminhadas, atrai } \\
\text { visitantes, tem sua beleza cênica } \\
\text { reconhecida por muitos } \\
\text { frequentadores" }\end{array}$ \\
\hline Relações sociais & Não & & \\
\hline Senso de lugar & Sim & $\begin{array}{l}\text { Valorização da importância do } \\
\text { local, reforçada pela } \\
\text { preocupação para que o } \\
\text { córrego se mantenha } \\
\text { despoluído. }\end{array}$ & $\begin{array}{l}\text { "a proximidade com a natureza e } \\
\text { melhoria da qualidade de vida é } \\
\text { vivenciada pela maioria dos } \\
\text { frequentadores" }\end{array}$ \\
\hline $\begin{array}{l}\text { Valores de patrimônio } \\
\text { cultural }\end{array}$ & Sim & $\begin{array}{l}\text { Criação de espaço com } \\
\text { significado cultural }\end{array}$ & $\begin{array}{l}\text { "embora a área seja recente, há } \\
\text { uma grande preocupação por } \\
\text { manutenção e melhorias, } \\
\text { configurando-a como relevante } \\
\text { para a região" }\end{array}$ \\
\hline $\begin{array}{l}\text { Recreação e } \\
\text { ecoturismo }\end{array}$ & Sim & $\begin{array}{l}\text { O uso da área para atividades } \\
\text { de lazer }\end{array}$ & $\begin{array}{l}\text { "a área tem grande atratividade } \\
\text { para uma série de atividades de } \\
\text { lazer, mas melhorias estão na lista } \\
\text { de solicitações" }\end{array}$ \\
\hline
\end{tabular}

Fonte: os autores.

Pela análise da Tabela 5, observa-se que metade das categorias de SEC (MEA, 2005) pode estar associada aos benefícios percebidos pelos entrevistados, aos quais puderam ser associadas representações sociais. Os benefícios identificados estão diretamente ligados à abordagem dos SEC em atividades como a despoluição de córregos urbanos, como discutidos por Agarwala et al. (2014) e puderam ser analisados pela observação direta junto à população, como apontado por Boithias et al. (2016).

Os frequentadores do córrego Charles de Gaulle expressam sentimentos como senso de lugar, saúde, tranquilidade, espaço para atividades lúdicas que são caracterizados por La Rosa et al. (2016), Fish et. al. (2016), Cheng et al. (2019) como benefícios associados a SEC. Boa parte dos entrevistados consegue observar e vivenciar melhorias do processo de revitalização do córrego, sugerindo que em locais onde prevalece integração da sociedade e meio ambiente podem ser ofertados SEC, conforme destacado por Gelcich \& O'Keeffe (2016) e Xiao et al. (2017). O engajamento de alguns frequentadores em manter as condições de despoluição do córrego e vivenciar os benefícios dessa requalificação urbana se coaduna ao verificado por Daniel et al. (2012) e Jennings et al. (2016).

A oferta de SEC em processos de despoluição e preservação de rios urbanos em diferentes cidades do mundo permite identificar benefícios similares aos percebidos pela população do caso em estudo como: governança (Kaval \& Belt, 2017), inserção social (Mihelcic et. al., 2017), retorno da população ao convívio com o córrego (Vogl et al., 2017). 
Os resultados da pesquisa confirmam os achados de Preston \& Raudsepp-Hearne (2017) e Dickinson \& Hobbs (2017), sobre as dimensões dos SEC estarem associadas às características da região e refletindo diretamente no bem-estar da população.

As cinco categorias de SEC e as respectivas representações sociais demonstram como discutido por Hegetschweiler et al. (2017), que os SEC oferecidos por um ambiente dependem das suas características físicas e das demandas ou fatores sociais como necessidades, preferências e valores. Assim, confirma-se a prevalência de SEC relacionados a interações pessoais, lazer, contemplação, espaço para manifestações em detrimento a SEC que possam ter uma influência para além do ambiente local e de uma perspectiva temporal mais ampla, de modo a gerar diversidade cultural, valores religiosos e espirituais, de educação e de sistemas de conhecimento e de relações sociais mais elaboradas.

\section{Conclusões}

A despoluição do córrego Charles de Gaulle do Programa Córrego Limpo (PCL), em São Paulo, propicia diversos benefícios percebidos pela população local que podem ser caracterizados como serviços ecossistêmicos culturais (SEC). Da percepção dos usuários do córrego, esses benefícios relacionam-se com valores para inspiração, estéticos, de pertencimento, de recreação e até de patrimônio cultural. Não se verificam valores referentes a desenvolvimento de relações sociais, de diversidade cultural, de valores religiosos, espirituais e educacionais e de sistemas de conhecimento.

Os SEC observados pela população frente ao córrego despoluído relacionam-se diretamente a sentimentos de pertencimento, de melhoria das condições atuais do entorno do córrego em relação às pretéritas, à contemplação de uma área recuperada e à oportunidade para realização de atividades esportivas ou sociais. Esses SEC são similares àqueles reconhecidos em outros processos de revitalização de cursos de água urbanos em cidades de diferentes países. A recuperação de áreas urbanas pode ensejar expectativas e possibilidades similares independente das condições socioeconômicas e culturais.

Conclui-se a predominância de SEC direcionados ao uso para interações pessoais, lazer, contemplação, espaço para manifestações sobre aqueles que possam revelar influência para além do ambiente local e temporal referentes a diversidade cultural, valores religiosos e espirituais, de educação e de sistemas de conhecimento.

A população que utiliza os espaços revitalizados do córrego Charles de Gaulle do PCL demonstra a existência de uma demanda por locais de integração entre homem e natureza. Assim, o processo de governança colaborativa, utilizado no escopo do PCL, poderia fortalecer a manutenção desses ambientes recuperados e ampliar a oferta de SEC para além dos percebidos pela população.

A perspectiva de oferta dos SEC pelas atividades do PCL no caso estudado permite a identificação de oportunidades para aprimoramento da gestão de processos de despoluição de córregos urbanos.

Essas áreas revitalizadas pela despoluição de córregos urbanos representam a condição mínima para que a população possa usufruir dos SEC, porém, considerar os efeitos positivos de despoluição do córrego apenas controlados pelos valores de DBO pode ser uma perspectiva reducionista de programas de políticas públicas que são caros e escassos para a população urbana.

A abordagem dos SEC pode ser inserida como mecanismo para avaliação da efetividade de programas de despoluição de córregos urbanos para além dos tradicionais indicadores de qualidade de água, como a DBO. Considera-se que essa abordagem permitiria introduzir uma mensuração, ainda que indicativa, da recuperação da integridade do sistema socioecológico de rios urbanos revitalizados. Esses esquemas poderiam, por meio de entrevistas de percepção e atitude sobre a despoluição de córregos urbanos, identificar os SEC ofertados criando escalas locais de valores e projetando perspectivas para a manutenção desses serviços. Uma potencial ampliação da oferta de SEC representaria melhorias da qualidade do ambiente local e dos benefícios culturais dessas áreas na cidade.

Entretanto, não se pode esperar que apenas os procedimentos de despoluição de córregos urbanos possam alavancar SEC complexos e mais abrangentes para além da escala local. Dentro do contexto de 
valorização do sistema hídrico e sistema de áreas verdes no planejamento urbano, a perspectiva de oferta dos SEC poderia ser ampliada considerando essa integração.

Por fim, considera-se que programas de recuperação de ambientes degradados urbanos são fundamentais para o bem-estar da sociedade e podem ser mensurados pelos SEC. Recomenda-se que estudos futuros desenvolvam critérios objetivos para valorar os SEC identificados nesta pesquisa, bem como para desenvolver escalas locais de benefícios culturais obtidos por esses programas. A apropriada identificação e consideração dos SEC na revitalização de rios urbanos permite alavancar benefícios decorrentes de políticas públicas para a população urbana, principalmente em cidades em que as oportunidades de lazer em contato com áreas verdes e úmidas são restritas.

\section{Agradecimentos}

A segunda autora agradece à Fundação de Amparo à Pesquisa do Estado de São Paulo (Fapesp), pelo apoio concedido ao financiamento da pesquisa que deu origem a este artigo científico, por meio do Processo Fapesp no 2019/18.988-9, e ao Conselho Nacional de Desenvolvimento Cientifico e Tecnológico (CNPq), sob Processo no 303542/2020-9, pelo apoio ao desenvolvimento da pesquisa realizada.

\section{Referências}

Agarwala, M., Atkinson, G., Fry, B. P., Homewood, K., Mourato, S., Rowcliffe, J. M., \& Milner-Gulland, E. J. (2014). Assessing the relationship between human well-being and ecosystem services: a review of frameworks. Conservation and Society, 12(4), 437-449.

Andersson, E., Tengö, M., McPhearson, T., \& Kremer, P. (2015). Cultural ecosystem services as a gateway for improving urban sustainability. Ecosystem Services, 12, 165-168.

Anelli, R. L. S. (2015). Uma nova cidade para as águas urbanas. Estudos avançados, 29(84), 69-84.

Avelar, A. B. A., da Silva-Oliveira, K. D., \& da Silva Pereira, R. (2019). Education for advancing the implementation of the Sustainable Development Goals: A systematic approach. The International Journal of Management Education, 17(3), 100322.

Bennett, N. J. (2016). Using perceptions as evidence to improve conservation and environmental management. Conservation Biology, 30(3), 582-592.

Bertram, C., \& Rehdanz, K. (2015). Preferences for cultural urban ecosystem services: Comparing attitudes, perception, and use. Ecosystem Services, 12, 187-199.

Boithias, L., Terrado, M., Corominas, L., Ziv, G., Kumar, V., Marqués, M., \& Acuña, V. (2016). Analysis of the uncertainty in the monetary valuation of ecosystem services-A case study at the river basin scale. Science of the Total Environment, 543, 683690.

Bryce, R., Irvine, K. N., Church, A., Fish, R., Ranger, S., \& Kenter, J. O. (2016). Subjective well-being indicators for large-scale assessment of cultural ecosystem services. Ecosystem Services, 21, 258-269.

Bullock, C., Joyce, D., \& Collier, M. (2018). An exploration of the relationships between cultural ecosystem services, sociocultural values and well-being. Ecosystem services, 31, 142-152.

Camargo, B. V., \& Justo, A. M. (2013). IRAMUTEQ: um software gratuito para análise de dados textuais. Temas em psicologia, 21(2), 513-518.

Cheng, X., Van Damme, S., Li, L., \& Uyttenhove, P. (2019). Evaluation of cultural ecosystem services: A review of methods. Ecosystem services, 37, 100925.

Cohen, J. B., \& Andrade, E. B. (2004). Affective intuition and task-contingent affect regulation. Journal of Consumer Research, 31(2), 358-367.

Cortinovis, C., \& Geneletti, D. (2018). Ecosystem services in urban plans: What is there, and what is still needed for better decisions. Land use policy, 70, 298-312. 
Costanza, R., d'Arge, R., De Groot, R., Farber, S., Grasso, M., Hannon, B., \& Raskin, R. G. (1997). The value of the world's ecosystem services and natural capital. Nature, 387(6630), 253-260.

Daniel, T. C., Muhar, A., Arnberger, A., Aznar, O., Boyd, J. W., Chan, K. M., ... \& Grêt-Regamey, A. (2012). Contributions of cultural services to the ecosystem services agenda. Proceedings of the National Academy of Sciences, 109(23), 8812-8819.

Dickinson, D. C., \& Hobbs, R. J. (2017). Cultural ecosystem services: Characteristics, challenges and lessons for urban green space research. Ecosystem Services, 25, 179-194.

Dictoro, V. P., Galvão, D. F., \& Hanai, F. Y. (2016). O estudo das representações sociais e da percepção ambiental como instrumentos de análise das relações humanas com a água. Ambiente \& Educação, 21(1), 232-251.

Dou, Y., Zhen, L., Yu, X., Bakker, M., Carsjens, G. J., \& Xue, Z. (2019). Assessing the influences of ecological restoration on perceptions of cultural ecosystem services by residents of agricultural landscapes of western China. Science of the Total Environment, 646, 685-695.

Fish, R., Church, A., \& Winter, M. (2016). Conceptualising cultural ecosystem services: A novel framework for research and critical engagement. Ecosystem Services, 21, 208-217.

Gelcich, S., \& O'Keeffe, J. (2016). Emerging frontiers in perceptions research for aquatic conservation. Aquatic Conservation: Marine and Freshwater Ecosystems, 26(5), 986-994.

Gómez-Baggethun, E., \& Barton, D. N. (2013). Classifying and valuing ecosystem services for urban planning. Ecological economics, 86, 235-245.

Hale, R. L., Cook, E. M., \& Beltrán, B. J. (2019). Cultural ecosystem services provided by rivers across diverse social-ecological landscapes: A social media analysis. Ecological Indicators, 107, 105580.

Hegetschweiler, K. T., de Vries, S., Arnberger, A., Bell, S., Brennan, M., Siter, N., \& Hunziker, M. (2017). Linking demand and supply factors in identifying cultural ecosystem services of urban green infrastructures: A review of European studies. Urban Forestry \& Urban Greening, 21, 48-59.

Heimerl, F., Lohmann, S., Lange, S., \& Ertl, T. (2014). Word cloud explorer: Text analytics based on word clouds. In $201447^{\text {th }}$ Hawaii International Conference on System Sciences (pp. 1833-1842). IEEE.

Jacobi, P. R., Fracalanza, A. P., \& Silva-Sánchez, S. (2015). Governança da água e inovação na política de recuperação de recursos hídricos na cidade de São Paulo. Cadernos Metrópole, 17(33), 61-81.

Jennings, V., Larson, L., \& Yun, J. (2016). Advancing sustainability through urban green space: Cultural ecosystem services, equity, and social determinants of health. International Journal of environmental research and public health, 13(2), 196.

Kaval, P., \& van den Belt, M. (2017). The Organizing Framework of Ecosystem Services and its use in River Management (No. $17 / 22)$.

Ko, H., \& Son, Y. (2018). Perceptions of cultural ecosystem services in urban green spaces: A case study in Gwacheon, Republic of Korea. Ecological indicators, 91, 299-306.

La Rosa, D., Spyra, M., \& Inostroza, L. (2016). Indicators of cultural ecosystem services for urban planning: a review. Ecological Indicators, 61, 74-89.

Laverie, D. A., Kleine III, R. E., \& Kleine, S. S. (2002). Reexamination and extension of Kleine, Kleine, and Kernan's social identity model of mundane consumption: The mediating role of the appraisal process. Journal of Consumer Research, 28(4), 659-669.

Macedo-Silva, W., Tchaicka, L., \& Sá-Silva, J. R. (2016). Representações Sociais e Percepção Ambiental: A Balneabilidade de Praias de São Luís e São José de Ribamar, Maranhão, Brasil-Social. Rosa dos Ventos - Turismo e Hospitalidade, 8(4), 405-418.

Millennium Ecosystem Assessment - MEA (2005). Ecosystems and human well-being (Vol. 5, p. 563). Washington, DC: Island Press.

Mihelcic, J. R., Naughton, C. C., Verbyla, M. E., Zhang, Q., Schweitzer, R. W., Oakley, S. M., \& Whiteford, L. M. (2017). The grandest challenge of all: The role of environmental engineering to achieve sustainability in the world's developing regions. Environmental Engineering Science, 34(1), 16-41.

Nascimento, A. R. A., \& Menandro, P. R. M. (2006). Análise lexical e análise de conteúdo: uma proposta de utilização conjugada. Estudos e pesquisas em psicologia, 6(2), 72-88. 
Nysveen, H., Pedersen, P. E., \& Thorbjørnsen, H. (2005). Intentions to use mobile services: Antecedents and cross-service comparisons. Journal of the academy of marketing science, 33(3), 330-346.

Oltramari, L. C., \& Camargo, B. V. (2010). Aids, relações conjugais e confiança: um estudo sobre representações sociais. Psicologia em estudo, 15(2), 275-283.

Plieninger, T., Dijks, S., Oteros-Rozas, E., \& Bieling, C. (2013). Assessing, mapping, and quantifying cultural ecosystem services at community level. Land use policy, 33, 118-129.

Pulighe, G., Fava, F., \& Lupia, F. (2016). Insights and opportunities from mapping ecosystem services of urban green spaces and potentials in planning. Ecosystem services, 22, 1-10.

Preston S., M., \& Raudsepp-Hearne, C. (2017). Completing and Using Ecosystem Service Assessment for Decision-Making: An Interdisciplinary Toolkit for Managers and Analysts Value of Nature to Canadians Study Taskforce Federal. Provincial, and Territorial Governments of Canada, Biodivcanada. ca.

Ramires Junior, S. P., das Neves, S. S., Ruiz, M. S., Gallardo, A. L. C. F., Côrtes, P. L., \& Cerântola, A. P. C. (2015). Governança colaborativa aplicada à gestão de conflitos socioambientais na despoluição de córregos na cidade de São Paulo. Revista Brasileira de Gestão e Desenvolvimento Regional, 11(1).

Ribeiro, J., de Souza, F. N., \& Lobão, C. (2018). Saturação da análise na investigação qualitativa: quando parar de recolher dados? Revista Pesquisa Qualitativa, 6(10).

Riechers, M., Barkmann, J., \& Tscharntke, T. (2016). Perceptions of cultural ecosystem services from urban green. Ecosystem Services, 17, 33-39.

Sabesp. Programa Córrego Limpo (2013). Companhia de Saneamento Básico do Estado de São Paulo. São Paulo, SP, Brasil, p. $1-47$

Stålhammar, S., \& Pedersen, E. (2017). Recreational cultural ecosystem services: How do people describe the value? Ecosystem Services, 26, 1-9.

Shimp, T. A., \& Stuart, E. W. (2004). The role of disgust as an emotional mediator of advertising effects. Journal of advertising, 33(1), 43-53.

Silva-Sánchez, S., \& Jacobi, P. R. (2012). Políticas de recuperação de rios urbanos na cidade de São Paulo. Possibilidades e Desafios. Revista Brasileira de Estudos Urbanos e Regionais, 14(2), 119-132

Souza, V. V. D. C. D., Gallardo, A. L. C. F., Côrtes, P. L., Fracalanza, A. P., \& Ruiz, M. S. (2018a). Pagamento por serviços ambientais de recursos hídricos em áreas urbanas: perspectivas potenciais a partir de um programa de recuperação da qualidade de água na cidade de São Paulo. Cadernos Metrópole, 20(42), 493-512.

Souza, M. A. R. D., Wall, M. L., Thuler, A. C. D. M. C., Lowen, I. M. V., \& Peres, A. M. (2018b). 0 uso do software IRAMUTEQ na análise de dados em pesquisas qualitativas. Revista da Escola de Enfermagem da USP, 52, 1-7.

Vinuto, J. (2014). A amostragem em bola de neve na pesquisa qualitativa: um debate em aberto. Temáticas, Campinas, 22(44), 203-220.

Vogl, A. L., Bryant, B. P., Hunink, J. E., Wolny, S., Apse, C., \& Droogers, P. (2017). Valuing investments in sustainable land management in the Upper Tana River basin, Kenya. Journal of environmental management, 195, 78-91.

Xiao, L., Haiping, T., \& Haoguang, L. (2017). A theoretical framework for researching cultural ecosystem service flows in urban agglomerations. Ecosystem Services, 28, 95-104.

Editor: Paulo Nascimento Neto

Recebido: 3 mai. 2020

Aprovado: 12 jan. 2021 